\title{
Carta del Factor de Potosí Juan Lozano Machuca (al virrey del Perú Don Martín Enríquez) en que da cuenta de cosas de aquella villa y de las minas de los Lipes (año 1581)
}

Transcripción de José MaRía CASASSAS

\section{[p. 144] Excmo. señor}

Carta del factor de Potosí Juan Lozano Machuca (al virrey del Perú Don Martín Enríquez) en que da cuenta de cosas de aquella villa y de las minas de los Lipes (y de atacama).

- Por dos que tengo escritas a V. Exca., he suplicado fuese V. Exca., servido aguardar a que Pedro Sande fuese a informar a V. Exca., de algunas cosas importantes, y estando ya Pedro Sande para se partir, la Real Audiencia de la Plata envió por él por cierto negocio que contra él trata el Fiscal sobre la herencia de su padre y sobre una negra que compró que estaba condenada a muerte y visto ésto determinó ir en su lugar Diego Enrique Franco que es el que ésta dará a V. Exca., que asimismo estaba determinado de ir con Pedro Sande, y atento a ésto me será forzado alargarme en ésta más de lo que lo hiciera yendo Pedro Sande. Será V. Exca., servido de mandarme dar para ello licencia.

- Habrá diez años poco más o menos que en el repartimiento de los Lipes, que está en la corona real como cincuenta leguas de esta Villa, se descubrieron muchas minas de plata y se comenzaron a registrar con mucha furia, y de la misma manera se dejaron de proseguir y labrar y así se quedaron por entonces, diciendo ser la tierra mala y despoblada. $Y$ después, habiendo yo venido a servir a su Majtd., en estos oficios de factor y veedor de su real hacienda, viendo lo mal que estos indios pagaban su tasa, traté con Tomás de Ybarra, Alguacil de hacienda real, cerca de la orden que se podría tener para la cobrar, porque se decía que eran indios belicosos y que estaban cerca de indios de guerra y no se sufría apretarlos porque no se alzasen. Tomás de Ybarra se ofreció a ir y yo le ayudé para ello y entender lo que en ésto había y así lo puso en ejecución, llevando tres o cuatro amigos consigo y recaudos de Oficiales Reales para cobrar la tasa. Y habiendo ido allá entendió que los indios eran muy ricos y que podían pagar a su majtd., mucha más tasa y que no eran belicosos como se decía sino muy al contrario, y a él le pareció la grangería de las minas tan bien que compró una y pidió otra por despoblada de que ha sacado metal muy rico.

- Y esto fue causa de que otra mina que su majtd., tenía cerca de la del Ybarra se arrendase por tres años a la mitad del metal que se sacase, libre de costas y más doscientos pesos en los tres años y el que la arrendó ha ganado más de tres mil pesos ensayados en hacer traspaso del arrendamiento. Y entendida esta noticia que me dio el Tomás de Ybarra, rogué a Pedro Sande que tomase trabajo de llegarse a ver aquellas minas e hiciese algún ingenio con que las desaguase porque estaban llenas de agua, por ser hombre ingenioso y general en muchas cosas, y que asimismo entendiese todo lo que había en la tierra y la disposición de ella muy

[p. $144 \mathrm{v}$ ]

en particular, ofreciéndole que procuraría se le gratificase su trabajo y que se llegase al asiento de Porco a ver las minas que su majtd., allí tiene para darme relación de todo. Púsolo en ejecución y fue a Porco y de su ida resultó descubrirse cierto arrendamiento que estaba hecho de una mina de su majtd., y díceme que aquellas minas de Porco están muy llenas de agua y conviene desaguarlas.

- Fue a los Lipes donde estuvo cuatro o cinco meses viendo y entendiendo la tierra y desaguando las minas que tenían mucha agua, y descubrió nueve vetas de plata en un cerro que llaman Escala, once leguas del asiento de Usloque que es donde primero se descubrieron las minas que he dicho y donde se arrendó la de su majtd., como verá V. Exca., en particular por la manifestación y relación quede ésto me trajo, que es la que sigue.

- El repartimiento de los Lipes está en Corona de su Majtd. Tendrá de box [?] el contorno y término de lo que se intitulan los Lipes trescientas leguas y habrá como cuatro mil indios aymaraes, antes más que menos, y éstos están por reducir, divididos en 
muchas partes y pueblos muy distintos y apartados unos de otros en las poblaciones siguientes: Colcha, que es el pueblo donde reside el sacerdote, y el pueblo de Chuquilla y Queme, Cheucha, Becaya, Ojas, Tuca, Palas, Patana, Abana, los cuales son pueblos principales del dicho distrito, y sin éstos habrá otros cien pueblezuelos de a 10, 20, 30, 50, 80 indios. Y en este repartimiento y tierra de los Lipes, con ser tan grande, hay sólo un sacerdote que es el padre Joan Mondragon, y no tienen suficiente doctrina por estar tan divididos, y apartados, que hay pueblos que están unos de otros 15, 20, 40, 50, 80 leguas y más, y ésto es causa de que los indios vivan sin orden ni policía de ley natural ni evangélica porque la mayor parte de todos ellos no son bautizados, ni se confiesan, ni tienen doctrina, ni participan de los sacramentos de la Santa Madre Iglesia.

- Demás de estos cuatro mil indios, junto al cerro de Escala, que es el que ahora Pedro Sande ha descubierto y registrado en él las minas de plata contenidas en la manifestación que lleva Diego Enrique con las muestras y ensayos, y asimismo de otro cerro en que registró una veta Agustín de Mondragon, que se llama Corotono, y está cuatro leguas de Usloque, junto al cerro de Escala, hay cuatro pueblos de indios uros que se llaman Pololo, Notuma, Horomita, Sochusa, que están a cuatro y cinco y siete y diez leguas del dicho cerro de Escala, y todos éstos son de su majtd., y no dan casi nada de tributo porque jamás han sido visitados y por tener fama aquella tierra de inhabitable y los indios pobres, por lo cual y por no estar reducidos se pierden y han perdido muchas almas por carecer de doctrina evangélica, como está dicho.

- Demás de los cuatro mil indios referidos habrá en este repartimiento otros mil indios uros, gente pobre que no siembran ni cogen y se sustentan de caza de guanacos y vicuñas y de pescado y de raíces que hay en ciénagas, que las llaman coroma. Y con éstos se hacen pobres los cuatro mil aymaraes, porque siendo gente rica de ganados de la tierra y que cogen y siembran y tienen contrataciones y rescates en esta villa de Potosí, Tarapacá y Atacama, y que funden muchos metales que sacan de las minas, se excusan de pagar tributo a su majtd., a título de pobres, como los mil indios uros que lo son verdaderamente, y podrían pagar muy descansadamente a su majtd., cada un año doce mil pesos ensayados de tasa, y ésto claramente se ha visto y entendido y se ve cada día, y lo principal a que fue Pedro Sande por orden mía fue a hacer esta averiguación, verificación y pesquisa de raíz, como la ha hecho con los mismos indios y por vista de ojos y asimismo me significa lo mucho que conviene al servicio de Dios nuestro Señor y al de su majtd., el reducir todos estos indios en dos o tres pueblos donde tengan comodidad de tierras y sementeras y doctrina bastante.

- Demás de ésto me ha advertido que los caciques Lipes, como gente de más razón y entendimiento que los demás indios, se sirven y aprovechan de los indios y los ocultan y aún venden unos a otros y cobran de ellos la tasa y se aprovechan de ella y no la meten en la Caja Real, y los propios indios se quejan de ésto.

\section{[p. 145]}

-Y asimismo dice hay otros indios que confinan con los indios de guerra de Omaguacas y Casabinbo y tienen trato y comercio con estos Lipes, los cuales están neutrales, que no son de paz ni de guerra, y entran en Potosí con nombre de indios Lipes y Atacamas, con ganados y otras cosas de venta y rescate, y se podrían con facilidad allanar y reducir a nuestra Santa Fe Católica y serían de mucho provecho por estar cerca del cerro de Escala y pagarían tasa a su majtd. que será de mucho interés.

- En el distrito de los Lipes hay otras muchas vetas de plata, cobre y plomo para artillería y munición, y salitre en cantidad para pólvora, de lo cual todo se puede sacar y hacer mucha suma para el servicio de su majtd. y provisión de este reino, por estar en parte y tierra tan cómoda para ello de leña, carbón y otros materiales, y aparejo para llevarlo a los puertos donde V. Exca., viese que conviene más al real servicio.

- Asimismo en todo el distrito de los Lipes, en las casas y rancherías de los indios hay hornillos de fundir y afinar plata y muchas guairas por los cerros y todos en general se ocupan de beneficiar y sacar plata, y no se sabe de las vetas de donde se saca, lo cual se sabría con facilidad si la dicha tierra se poblase y hollase de españoles.

- Estos indios son extremamente viciosos en comer coca y tienen de gasto ordinario de ella cada año más de diez mil pesos ensayados, porque todo el rescate que tienen en esta Villa de Potosí es llevar coca solamente a su tierra, aunque es gente que no se emborracha ni acostumbran a beber chicha por no ser la tierra dispuesta ni aparejada para dar maíz. 
- Parece que al tiempo que se hizo la visita general por el señor don Francisco de Toledo, no se visitaron ni redujeron estos indios lipes por tener fama de tierra pobre y cercanos de los de guerra y porque dos caciques de ellos se presentaron en esta Villa ante el señor don Francisco de Toledo haciéndole presente de unas plumas de avestruces y una camiseta de unos animalejos terrestres que llaman chinchillas y significándole ser gente tan pobre que no alcanzaban sino aquello que le presentaban, y así el día de hoy traen por refrán los dichos indios que dos indios engañaron a un visorrey. $\mathrm{Y}$ parece haber sido la voluntad de Dios para que de mano de V. Exca., se haga esta reducción y descubrimiento y un efecto de tanto servicio de Dios Nuestro Señor y de aumento de la real hacienda y bien a los naturales, estando en policía y teniendo doctrina vivirán más cristianamente y conforme a razón y serán más ricos.

- El valle de Atacama está de los Lipes 40 leguas. Son indios encomendados a Juan Velasquez Altamirano, vecino de la Plata, y si V. Exca., acomodase en otra cosa al Juan Velazquez, de lo cual él holgaría de buena gana, porque no le dan de provecho más que mil pesos mal pagados cada año, se podrían poner estos indios atacamas en la Corona real y reducirse en uno o dos pueblos, que serán hasta dos mil indios; demás del tributo que darían a su majtd., se podrían labrar muchas minas de cobre que hay en aquella comarca, en especial en el mismo puerto de Atacama, a la lengua del agua y partes donde con cinceles se podrá cortar el cobre fino como V. Exca., lo verá por la muestra que lleva Diego Enriquez.

- En la ensenada de Atacama que es donde está el puerto hay cuatrocientos indios pescadores, uros que no son bautizados ni reducidos ni sirven a nadie, aunque a los caciques de Atacama dan pescado en señal de reconocimiento. Es gente muy bruta, no siembran ni cogen y susténtanse de sólo pescado y están juntos a esta veta de cobre, y así con estos indios y los atacamas se podría labrar esta veta y sería de gran provecho a su majtd. por estar tan junto al puerto y poderse llevar cobre por todo el reino y a España por el estrecho. En este puerto es donde dio carena a su navío e hizo su lancha el inglés Francisco [Drake], por ser de los mejores puertos que esta mar tiene. Será esta ensenada de veinte leguas y en ella se ofrece Pedro Sande a que se cogerá mucho ámbar, que ahora se la comen los pájaros, y dará para ello industria. [p. $145 \mathrm{v}$ ]

- Y podríase compeler a los indios de Atacama que diesen mantenimientos a estos indios que allí trabajasen, tasándolos a moderados precios, conforme a la disposición de la tierra, atento que no tienen saca de ellos a ninguna parte, y tasando los jornales de los indios conforme a ésto, porque de otra manera no se podrá conseguir este buen efecto.

- Y de esta manera se podrá dar en muchas minas de oro y plata y otros metales, porque los hay en la tierra, y es fama común que los caciques principales los tienen oculto [sic] a fin de que españoles no les entren en sus tierras y porque el diablo se lo aconseja, y para ésto sería necesario tener siempre en Potosí o en la ciudad de la Plata dos o tres caciques de los principales en depósito y rehenes, hasta que esté bien entablado, por ser indios belicosos y mal impuestos.

- Y con estos indios atacamas y cien españoles se podría conquistar toda la tierra de Omaguaca, que está cuarenta leguas de Atacama y se tratan y tienen rescate entre ellos de oro y plata y saben toda la tierra. $\mathrm{Y}$ los Omaguacas es poca gente y tienen mucho ganado de la tierra y mucho oro y plata.

- Hay en este valle de Atacama y contorno de él lápiz azul y jaspe de colores diferentes y negros y amarillos, turquesas finas y granates y otras diferencias de piedras de poco valor y mucho, y así mismo en Tarapacá hay algunas cosas de éstas y alumbre muy rico.

- Podríase abrir camino desde el asiento de Escala a Copiapó de Chile por la cordillera, y hay agua y pasto y mucho ganado vacuno que vale a peso cada novillo y vaca en Chile. Demás del provecho que se seguiría en traer y sacar el dicho ganado, sería de grandísimo provecho descubrir este camino por la cordillera a Chile, porque se excusaría el despoblado que hay a Chile desde Atacama a Copiapó, porque en él no hay el recaudo que habría por las vertientes de la cordillera donde Pedro Sande dice se abrirá camino y se ofrece a lo abrir.

- Asimismo, en el término y contorno de Tarapacá, que es desde el puerto de Pisagua y Hiquehique, donde hay indios uros pescadores, hasta el puerto de Loa, hay muchas minas de plata y oro, cobre y plomo, alumbre, acije (aceche, caparrosa) y otros metales. Y el inca pretendió echar el río de Mauri, 
que es en la cordillera, al valle del algarrobal, que es junto a Tarapacá y cinco leguas del cerro que llaman Asino, donde labró el inca y Lucas Martín Begasso y Pedro Sande ha labrado y vistolo por vista de ojos, y este río intentó el inca echarlo al algarrobal dicho y para ello rompió siete leguas de tierra y lo dejó como entraron los españoles en la tierra, y faltará por romper un cuarto cíe legua de la cordillera, que se podrá romper y abrir con costa de seis mil pesos ensayados y sería de muy grande efecto echar este río para cultivar las minas porque son muy ricas y es tierra fértil y abundante de comida, y si se echase este río se podrían poblar dos o tres pueblos de españoles y reducir los indios de aquel distrito, porque aunque se mandaron reducir en la visita general no están todos reducidos y se podrían sacar más de mil indios más de los reducidos, que están ocultos, y por ser tierra tan poco hollada de españoles no se han descubierto grandes riquezas que el inca labraba en ella. Y el repartimiento de los herederos de Lucas Martín Begasso es jurisdicción de la ciudad de Arequipa y tendrá como dos mil indios aymares [sic] y más de mil indios uros pescadores en el dicho distrito.

- Hay de los Lipes a Tarapacá 30 leguas.

- Hay desde los Lipes a Atacama 40 leguas.

- Hay desde los Lipes a los Carangas 40 leguas.

- Hay a Potosí desde los Lipes 50 leguas.

- Hay de los Lipes a Talina 35 leguas.

[p. 146]

- Hay de los Lipes a Tarija 40 leguas.

- Hay de los Lipes a la tierra de guerra de los Omaguacas 40 leguas.

- Hay de los Lipes a los indios cimarrones que están hacia Omaguaca 25 leguas.

- Puedense proveer los Lipes de comida de Tarapacá y de Atacama y de Talina y Tarija, y al presente se ha llevado de Potosí.

- Y para que V. Exca., más en particular entienda lo dicho y casi será verlo por vista de ojos, lleva Diego Enrique la pintura y discreción de toda esta tierra.

- Del contorno y tierras del Paraguay se podrían sacar con facilidad cuatro mil indios guaranís, gente muy belicosa y guerrera porque son casi los indios del Brasil, y hablan la propia lengua, y podríanse sacar por Tucumán para llevar a Chile, teniendo depósito de comida en la tierra de Tucuma [sic] que es muy abundante de maíz y carne y vale poco, y con estos indios y con doscientos o doscientos y cincuenta españoles se podría entrar a Chile con facilidad y apretando a los indios del Valle de Arauco y todos los demás que están de guerra por la otra parte y por ésta, con facilidad se hallanarían y se haría grandísimo servicio a Dios y a la majtd. real, porque estos indios, pasando la cordillera, correrán todo el estado de Arauco en pocos días, porque es gente de montaña y pelean con flechas y macanas y es gente que jamás representa batalla sino que dan los asaltos con muchas trasnochadas, en lo cual tienen grandísima ventaja a la gente de Chile. Y estos indios ahora diecisiete años salieron con Nuflo de Chaves y el Obispo del Paraguay y vinieron rodeando y hallanando la tierra, antes que llegasen a Santa Cruz, más de ochocientas leguas, y pasaron por gentes muy belicosas, y especial por la provincia que llaman Chiquitos, gente muy belicosa y que tiene hierba, y estos guaraníes vencieron y a otros muchos hasta llegar a Santa Cruz. Por manera que se tiene ya experiencia de esta gente.

- De la parte donde se han de sacar estos indios su majtd. no tienen ingún provecho de tasa ni de servicio de los indios, ni aún de los españoles ni criollos. Es gente muy buena para la guerra y buenos arcabuceros y hombres de a caballo y holgarán servir en esta jornada, y de Tucumán, como está dicho, se podrían proveer depósitos de comidas pues las tienen de cosecha y valen tan poco y aquella tierra no da ningún provecho.

- Siendo V. Exca., servido, yo me ofrezco entablar lo de los Lipes a ir a reducir todos aquellos indios, conforme a lo que está dicho en esta relación, y llevar la gente necesaria para ello, todo a mi costa y sin que se me dé socorro alguno. Y entiendo, mediante Dios, hacer en ello un señalado servicio a su majtd. y a V. Exca., porque creo ha de ser de tanta grosedad como este cerro, y holgaré en cosa semejante emplear mi vida y hacienda. Y asimismo, siendo V. Exca., servido y pareciendo que es cosa conveniente me ofrezco a entrar a socorrer a Chile con los indios arriba referidos o sin ellos, como mejor paresciere convenir, porque como hombre que trajo el socorro pasado para aquel Reino, deseo llevar este otro para lo allanar, porque como es cosa nueva acometerles por la parte del Perú, hanlo de extrañar, y aunque les pese se han de allanar.

- Con el talento que Dios me dio y con mi persona y hacienda y con mis amigos y deudos 
me ofrezco a servir en estas cosas. V. Exca., como quien tan bien entiende, será servido de

[p. $146 \mathrm{v}$ ]

mandar ver si conviene aceptar mi servicio y ofrecimiento y remitiéndome a Diego Enrique en las demás particularidades que V. Exca., fuere servido saber, Nuestro Señor la Excma. persona de V. Exca., guarde por muchos años y en mayor estado acreciente. En Potosí 8 de noviembre 1581.
- Pedro Sande es la persona que dio orden en hacer las lagunas de esta villa con que se muelen los ingenios de la ribera de ella muchos meses más de los que molieran, de que se sigue grandísima riqueza.

- Excmo. Señor De V. Excma. criado que sus excmas. manos besa Joan Loçano Machuca [rubricado]. 